\title{
Comparison of outcomes of conventional transcanalicular laser dacryocystorhinostomy and modified transcanalicular laser dacryocystorhinostomy
}

\author{
Senay Asik Nacaroglư ${ }^{1}$, Sahin Ogreden ${ }^{2}$, Ahu Yılmaz ${ }^{1}$, Kursat Atalay ${ }^{1}$, Ahmet Kırgız ${ }^{1}$ \\ ${ }^{1}$ Department of Ophthalmology, University of Health Sciences, Bagcilar Training and Research Hospital, Istanbul, Turkey \\ ${ }^{2}$ Department of Otolaryngology, University of Health Sciences, Bagcilar Training and Research Hospital, Istanbul, Turkey
}

Videosurgery Miniinv 2018; 13 (3): 401-406

DOI: https://doi.org/10.5114/wiitm.2018.77054

\begin{abstract}
Introduction: Transcanalicular laser DCR (TL-DCR) approaches have been developed for the formation of a fistula between the nasal cavity and the lacrimal sac to ensure the continuity of the lacrimal drainage system over the years. However, the success rate of TL-DCR has varied widely.

Aim: To evaluate and compare the success rates of conventional transcanalicular multidiode laser dacryocystorhinostomy and modified transcanalicular multidiode laser dacryocystorhinostomy.

Material and methods: Ninety-one eyes of 91 adult patients admitted with epiphora and diagnosed with chronic dacryocystitis were included in the study. The participants were divided into two groups. Group 1 consisted of 55 patients who were treated with conventional transcanalicular laser dacryocystorhinostomy. Group 2 consisted of 36 patients to whom the same surgical procedure was applied with the difference of nasal mucosa excision prior to laser osteotomy. The groups' intraoperative surgical ostium size, perioperative and postoperative complications, operative times and success rates were compared.

Results: The mean follow-up periods for each group were $8.88 \pm 2.99$ months and $10.28 \pm 4.47$ months, respectively $(p=0.077)$. Intraoperative mean surgical ostium sizes were $31.85 \pm 14.98 \mathrm{~mm}^{2}$ and $42.25 \pm 18.09 \mathrm{~mm}^{2}$, respectively $(p=0.004)$. The mean operation time in group 1 was significantly shorter compared to group $2(18.55 \pm 4.05$ min and $24.44 \pm 3.18 \mathrm{~min}$, respectively, $p=0.0001$ ). The overall success rate was $65.45 \%$ in group 1 and $75.00 \%$ in group 2 ( $p=0.335)$.

Conclusions: Although the surgical ostium area was significantly greater in group 2, there was no significant difference in surgical success and patient satisfaction rates between the two groups.
\end{abstract}

Key words: primary acquired nasolacrimal duct obstruction, laser dacryocystorhinostomy, modified transcanalicular laser dacryocystorhinostomy.

\section{Introduction}

External dacryocystorhinostomy (E-DCR) is the gold standard in the treatment of primary acquired nasolacrimal duct obstruction (PANDO) [1, 2]. Endoscopic dacryocystorhinostomy (EN-DCR) and transcanalicular laser DCR (TL-DCR) approaches have been developed for the formation of a fistula between the nasal cavity and the lacrimal sac to ensure the continuity of the lacrimal drainage system over the years. Among these procedures, TL-DCR causes a faster return to daily life, less hemorrhage, and a better cosmetic result [3]. This is precisely why

\section{Address for correspondence}

Senay Asik Nacaroglu MD, Department of Ophthalmology, University of Health Sciences, Bagcilar Training and Research Hospital,

34212 Istanbul, Turkey, fax: +90 5056071390, e-mail: asksenay@yahoo.com 
patients and specialists prefer this surgical method. However, TL-DCR may cause collateral tissue damage by laser energy and create smaller rhinostomies than the external and endonasal surgical approach. The success rate of TL-DCR has varied widely, between $46 \%$ and $90 \%$, in previous studies [4-12]. Attempts to improve the surgical success rate have been made through many methods such as surgical ostium expansion with endonasal forceps, the use of antimetabolite and different laser types [9].

\section{Aim}

In the present study, comparison of the effect of nasal mucosal removal prior to laser on the surgical success rate with standard TL-DCR was investigated.

\section{Material and methods}

\section{Subjects and selection criteria}

This prospective interventional study was conducted in the Bagcilar Research and Training Hospital of the University of Health Sciences, Department of Ophthalmology, between March 2016 and December 2017. The study was conducted in accordance with the guidelines of the Declaration of Helsinki. Ethics committee approval was obtained for the study, and all patients were informed about the surgical interventions and signed informed consent forms after the interview. Ninety-one eyes of 91 patients who were admitted to the outpatient clinic of the Ophthalmology Department with epiphora and who were diagnosed with PANDO were included in the study. Probing and irrigation of the canalicular system were performed for the nasolacrimal duct obstruction diagnosis. All patients were evaluated with a nasal endoscope by an otolaryngologist. Patients under the age of 18 years, with secondary lacrimal obstruction, ectropion, entropion, a history of trauma, common canalicular obstruction, prominent nasal septal deviation, nasal synechiae, polyps, and those who had previously undergone dacryocystorhinostomy surgery were excluded from the study. The participants were divided into two groups. Group 1 consisted of 55 patients who were treated with conventional transcanalicular laser dacryocystorhinostomy (CTL-DCR). Group 2 consisted of 36 patients to whom the same surgical procedure was applied with the difference of nasal mucosal excision prior to laser osteotomy (METL-DCR).

\section{Surgical procedure}

All operations were performed by the same surgeons under general anesthesia so that patient compliance could be standardized (SAN, SO). In both groups, Jetokain ampul by Adeka (lidocaine $\mathrm{HCl}$ $20 \mathrm{mg} / \mathrm{ml}$, epinephrine $\mathrm{HCl} 0.0125 \mathrm{mg} / \mathrm{ml}$ ) and adrenaline-soaked cotton were applied for $5 \mathrm{~min}$ to the nasal cavity. The superior and inferior puncta were dilated with a punctum dilator and then irrigated by saline solution $(0.9 \% \mathrm{NaCl}$ isotonic solution). A $980 \mathrm{~nm}$ multi-diode laser was used. A semirigid 600- $\mu \mathrm{m}$ quartz multi-diode laser fiber (Multidiode S30 OFT, INTERmedic Arfran, Madrid, Spain) was inserted through the inferior punctum and pushed into the sac. It was obliquely directed to the medial wall of the lacrimal sac. The laser was set at a power of $12 \mathrm{~W}$ and a pulse length of $400 \mathrm{~ms}$ with a 400 -millisecond pause between pulses. The laser power and the pulse length were adjusted according to impact. A zero degree rigid endoscope and aspiration probe were inserted endonasally, and the red light of the laser probe was observed from the sac wall. An osteotomy was opened by laser shots in the patients in group 1. The same procedure was applied to the patients in group 2; however, before opening an osteotomy by a laser, unlike group 1, lidocaine was injected into the nasal mucosa of the region where it was planned to open an osteotomy. The rectangular nasal mucosa of approximately $8 \times 5 \mathrm{~mm}$ was incised using a sickle edge blade anterior to the maxillary line underneath the adhesion site of the middle concha, and the mucosal flap was removed with the periosteal elevator and excised with alligator forceps. Then, the osteotomy was opened using laser energy. After sufficient space was achieved, drainage was checked by performing irrigation. Bicanalicular silicone tube intubation was performed in both groups. Oral amoxicillin/clavulanic acid, and nasal washes with saline were applied twice daily for 1 week after surgery. Netilmicin/dexamethasone eye drops four times daily and topical nasal treatment with fluticasone furoate were applied for a total of 4 weeks. The controls were performed on postoperative day 1 , in postoperative week 1 , month 1, month 3, month 6 and month 12. Anatomical success was demonstrated by the fact that the lacrimal system irrigation was open, and functional success was demonstrated by the ending of the patient's watering-eye complaints. 


\section{Statistical analysis}

In this study, statistical analyses were performed using the NCSS (Number Cruncher Statistical System) 2007 Statistical Software (Utah, USA) package. In addition to descriptive statistical methods (mean, standard deviation), Student's $t$-test for the comparison of paired groups, and the $\chi^{2}$ test for the comparison of qualitative data were used in the evaluation of data. The Kaplan-Meier test and the log-rank test were used in the survival analysis. The results were evaluated at a significance level of $p<0.05$.

\section{Results}

The average age of 55 patients in group 1 (35 females and 20 males) was $52.76 \pm 16.1$ years, while the average age of 36 patients in group 2 (24 females and 12 males) was $51.89 \pm 14.55$ years ( $p=$ $0.793)$. The most frequent complaints on admission of the patients were watering of eyes, lacrimal sac mucocele, and eye gunk, respectively. When the pre- operative endoscopic nasal passage was evaluated, no difference was observed between nasal pathologies in group 1 and group $2(p=0.675)$ (Table I). The mean surgical ostium area was $31.85 \pm 14.98 \mathrm{~mm}^{2}$ in group 1 and $42.25 \pm 18.09 \mathrm{~mm}^{2}$ in group 2 $(p=0.004)$. The mean operation time in group 1 was $18.55 \pm 4.05 \mathrm{~min}$, while the mean operation time in group 2 was $24.44 \pm 3.18 \mathrm{~min}$. The mean operation time of group 2 was found to be statistically significantly higher than that of group $1(p=0.0001)$. The mean time of silicone tube removal of group 1 and group 2 was found to be similar (4.06 \pm 0.83 months and $4.13 \pm 1.36$ months, $p=0.790$, respectively). The mean follow-up periods of the groups were also found to be similar (Table II). The anatomical success rate was $65.45 \%$ in group 1 and $75 \%$ in group 2 $(p=0.335)$, while the functional success rate was $72.7 \%$ in group 1 and $66.7 \%$ in group $2(p=0.536)$. The comparison between the groups with respect to time to primary loss of patency was performed by the Kaplan-Meier survival analysis method and the

Table I. Comparison of groups' demographic data and preoperative findings

\begin{tabular}{|c|c|c|c|c|c|}
\hline \multirow{2}{*}{$\begin{array}{l}\text { Parameter } \\
\text { Age }\end{array}$} & \multicolumn{2}{|c|}{$\begin{array}{c}\text { Group } 1 \text { (CTL-DCR) } \\
(n=55)\end{array}$} & \multicolumn{2}{|c|}{$\begin{array}{c}\text { Group } 2 \text { (METL-DCR) } \\
(n=36)\end{array}$} & $P$-value \\
\hline & \multicolumn{2}{|c|}{$52.76 \pm 16.1$} & \multicolumn{2}{|c|}{$51.89 \pm 14.55$} & 0.793 \\
\hline \multicolumn{5}{|l|}{ Gender: } & \multirow[t]{3}{*}{0.767} \\
\hline Male & 20 & $36.36 \%$ & 12 & $33.33 \%$ & \\
\hline Female & 35 & $63.64 \%$ & 24 & $66.67 \%$ & \\
\hline \multicolumn{5}{|l|}{ Complaint: } & \multirow[t]{5}{*}{0.472} \\
\hline Watering & 37 & $67.27 \%$ & 29 & $80.56 \%$ & \\
\hline Eye gunk & 5 & $9.09 \%$ & 3 & $8.33 \%$ & \\
\hline Mucocele & 11 & $20.00 \%$ & 3 & $8.33 \%$ & \\
\hline Dacryocystitis & 2 & $3.64 \%$ & 1 & $2.78 \%$ & \\
\hline \multicolumn{5}{|l|}{ Side: } & \multirow[t]{3}{*}{0.608} \\
\hline Right eye & 29 & $52.73 \%$ & 17 & $47.22 \%$ & \\
\hline Left eye & 26 & $47.27 \%$ & 19 & $52.78 \%$ & \\
\hline \multicolumn{5}{|l|}{ Nasal examination: } & \multirow[t]{5}{*}{0.675} \\
\hline Normal & 34 & $61.82 \%$ & 25 & $69.44 \%$ & \\
\hline Mild septal deviation & 13 & $23.64 \%$ & 8 & $22.22 \%$ & \\
\hline Bifid middle turbinate & 5 & $9.09 \%$ & 1 & $2.78 \%$ & \\
\hline Uncinate process & 3 & $5.45 \%$ & 2 & $5.56 \%$ & \\
\hline
\end{tabular}


Table II. Comparison of peroperative and postoperative data

\begin{tabular}{|c|c|c|c|}
\hline Parameter & $\begin{array}{c}\text { Group } 1(\mathrm{CTL}-\mathrm{DCR}) \\
(n=55)\end{array}$ & $\begin{array}{c}\text { Group } 2 \text { (METL-DCR) } \\
(n=36)\end{array}$ & $P$-value \\
\hline Operation time [min] & $18.55 \pm 4.05$ & $24.44 \pm 3.18$ & 0.0001 \\
\hline Surgical ostium area $\left[\mathrm{mm}^{2}\right]$ & $31.85 \pm 14.98$ & $42.25 \pm 18.09$ & 0.004 \\
\hline \multicolumn{3}{|l|}{ Day 1 control: } & \multirow[t]{4}{*}{0.321} \\
\hline Normal & $81.82 \%$ & $69.44 \%$ & \\
\hline Eye lid edema & $10.91 \%$ & $22.22 \%$ & \\
\hline Ecchymoses & $7.27 \%$ & $8.33 \%$ & \\
\hline \multicolumn{3}{|c|}{ Month 1 control (Lacrimal system irrigation): } & \multirow[t]{3}{*}{0.336} \\
\hline Patent & $96.36 \%$ & $91.67 \%$ & \\
\hline Closed & $3.64 \%$ & $8.33 \%$ & \\
\hline \multicolumn{3}{|l|}{ Postoperative complaint: } & \multirow[t]{5}{*}{0.825} \\
\hline None & $60.00 \%$ & $50.00 \%$ & \\
\hline Mild watering & $10.91 \%$ & $13.89 \%$ & \\
\hline Distinct watering & $16.36 \%$ & $19.44 \%$ & \\
\hline Itching & $12.73 \%$ & $16.67 \%$ & \\
\hline Silicone tube excision time [month] & $4.06 \pm 0.83$ & $4.13 \pm 1.36$ & 0.790 \\
\hline Follow-up time [month] & $8.88 \pm 2.99$ & $10.28 \pm 4.47$ & 0.077 \\
\hline Anatomical success rate & $65.45 \%$ & $75.00 \%$ & 0.335 \\
\hline Functional success rate & $72.7 \%$ & $66.7 \%$ & 0.536 \\
\hline
\end{tabular}

Significance $p<0.05$.

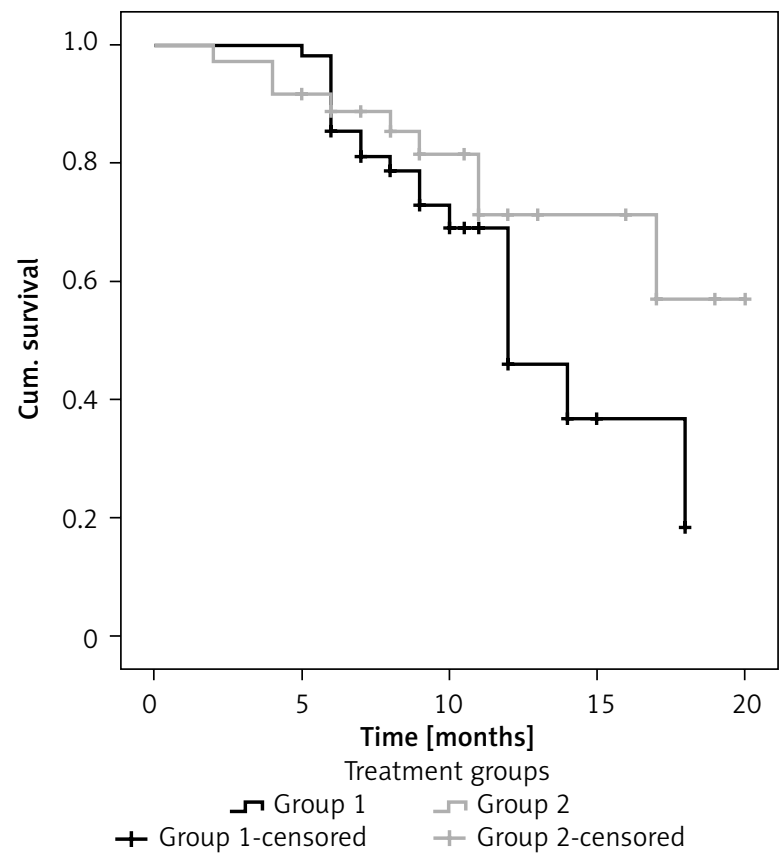

Figure 1. Survival graph of the surgical success of group 1 and group 2 log-rank test (Figure 1). The Kaplan-Meier survival analysis revealed no difference between the cumulative survival curves of the groups $(p=0.146)$.

\section{Discussion}

The success of the transcanalicular laser DCR method in the treatment of primary acquired nasolacrimal duct obstructions varies between $46 \%$ and $90 \%$ according to the type of the laser used, patient selection and the surgical method [10-12]. Various lasers such as holmium:yttrium-aluminum-garnet (Ho:YAG) laser, neodymium:YAG (Nd:YAG) laser, erbium:YAG (Er:YAG) laser and multidiode laser were used in transcanalicular DCR surgery to increase the surgical success rate [5, 10-12]. The most preferred 810 and $980 \mathrm{~nm}$ wavelength diode lasers are used nowadays. In the study carried out by Gupta et al. [11] on 94 patients with an $810 \mathrm{~nm}$ wavelength diode laser, they reported surgical success in $90.5 \%$ of patients. Patel et al. [12] reported low surgical success rates $(46 \%)$ after revision surgery in patients 
with failed external DCR with neodymium:YAG laser. They stated that they did not recommend the use of neodymium:YAG laser for revision in patients who had previously undergone DCR surgery because the success rates were so low. In the present study, a $980 \mathrm{~nm}$ wavelength diode laser was used. Patients with endonasal variations should be well evaluated and selected to increase surgical success with laser DCR. In a study in which Raposo et al. [13] evaluated the effect of septum deviation on laser DCR prognosis, the researchers found that mild and moderate septal deviation did not affect surgical success. In another study in which the prognostic effect of age in patient selection was evaluated, it was found that 6.76 times more successful surgical outcomes were obtained with laser DCR in patients aged 60 years and above compared to patients aged 20-30 years [14]. Similarly, in a study carried out by Kar et al. [15], they found out that age may be a significant factor influencing the surgical outcome of TL-DCR. In the present study, the average age of the patients was 52 years, which was similar in both groups, and the patients with nasal variations except for mild septum deviation during the endonasal examination were not evaluated. With laser DCR, DCR operation times have been significantly shortened, and surgical complications such as hemorrhage are less common $[2,3,16]$. In the present study, although the mean operation time of the group with nasal mucosal removal was longer compared to the conventional group, this difference was not clinically significant.

Surgical ostium and lacrimal fistula can be obstructed because mucosal flaps cannot be created in laser DCR. Recently, surgeons have tried methods such as the use of low energy lasers [10, 12], early cleaning of the surgical ostium [17], surgical ostium mitomycin C (MMC) application $[15,18]$, and laser-assisted dacryocystorhinostomy with endonasal augmentation with punch $[9,19,20]$ to decrease fibrous scar formation. Along with photothermal damage caused by the laser, increased fibroblastic activity in the nasal mucosa [21], scar formation and narrowing in the ostium can be observed. In a recent study carried out by Feijo et al. [16], they compared patients who underwent nasal mucosa excision prior to laser DCR and MMC after opening an osteotomy with patients who underwent conventional laser DCR. Although the anatomical and functional success rates in month 12 were higher in the first group, the difference was not statistically significant.
In the present study, similarly, the nasal mucosa was excised prior to the laser, and dissimilarly we did not perform MMC application, so we aimed to be protected from the possible adverse effects of MMC by avoiding the fibroblastic activity of the laser in the mucosa. Some studies report that the size of the osteotomy is not correlated with surgical success [22, 23]. Nevertheless, the size of the osteotomy is still believed to be the essential factor of surgical success in DCR [24]. The peroperative surgical ostium area was found to be significantly greater in cases undergoing nasal mucosa excision compared to the conventional group. However, although the anatomical success rate in the present study was higher in the group administered with mucosal excision, this difference was not statistically significant. Similarly, no statistically significant difference was observed between the groups in terms of functional success. The present study did not reveal any superiority of nasal mucosal excision added to laser DCR over conventional laser DCR. However, more extensive studies are required, with a larger sample size and longer follow-up time.

\section{Conclusions}

Laser DCR modifications that are fast, effective and have fewer complications can be used with increased success rates in well-selected patients. Although in the present study the surgical ostium area was significantly greater in group 2, there was no significant difference in surgical success and patient satisfaction rates between the two groups.

\section{Conflict of interest}

The authors declare no conflict of interest.

\section{References}

1. Tarbet KJ, Custer PL. External dacryocystorhinostomy. Surgical success, patient satisfaction, and economic cost. Ophthalmology 1995; 102: 1065-70.

2. Hartikainen J, Grenman R, Puukka P, et al. Prospective randomized comparison of external dacryocystorhinostomy and endonasal laser dacryocystorhinostomy. Ophthalmology 1998; 105: 1106-13.

3. Lee S, Yen MT. Laser-assisted dacryocystorhinostomy: a viable treatment option? Curr Opin Ophthalmol 2011; 22: 413-8.

4. Hong JE, Hatton MP, Leib ML, et al. Endocanalicular laser dacryocystorhinostomy analysis of 118 consecutive surgeries. Ophthalmology 2005; 112: 1629-33.

5. Kaynak P, Ozturker C, Yazgan S, et al. Transcanalicular diode laser assisted dacryocystorhinostomy in primary acquired 
nasolacrimal duct obstruction: 2-year follow up. Ophthal Plast Reconstr Surg 2014; 30: 28-33.

6. Ajalloueyan M, Fartookzadeh M, Parhizgar H. Use of laser for dacrocystorhinostomy. Arch Otolaryngol Head Neck Surg 2007; 133: 340-3.

7. Uysal IO, Ozçimen M, Yener HI, et al. Pediatric endocanalicular diode laser dacryocystorhinostomy: results of a minimally invasive surgical technique. Eur Arch Otorhinolaryngol 2011; 268: 1283-8.

8. Balikoglu-Yilmaz M, Yilmaz T, Taskin U, et al. Prospective comparison of 3 dacryocystorhinostomy surgeries: external versus endoscopic versus transcanalicular multidiode laser. Ophthal Plast Reconstr Surg 2015; 31: 13-8.

9. Goel R, Nagpal S, Kumar S, et al. Transcanalicular laser-assisted dacryocystorhinostomy with endonasal augmentation in primary nasolacrimal duct obstruction: our experience. Ophthal Plast Reconstr Surg 2017; 33: 408-12.

10. Drnovsek-Olup B, Beltram M. Transcanalicular diode laser-assisted dacryocystorhinostomy. Indian J Ophthalmol 2010; 58 213-7.

11. Gupta SK, Kumar A, Agarwal S, Pandey P. Transcanalicular laser dacryocystorhinostomy using low energy $810 \mathrm{~nm}$ diode laser. Oman J Ophthalmol 2012; 5: 171-4.

12. Patel BC, Phillips B, McLeish WM, et al. Transcanalicular neodymium: YAG laser for revision of dacryocystorhinostomy. Ophthalmology 1997; 104: 191-7.

13. Raposo A, Piqueras F, García-Purriños F, et al. Influence of septal deviation on the prognosis of transcanalicular diode laser-assisted dacryocystorhinostomy. I Ophthalmol 2016; 2016: 9573760.

14. Ayintap E, Buttanri IB, Sadıgov F, et al. Analysis of age as a possible prognostic factor for transcanalicular multidiode laser dacryocystorhinostomy. J Ophthalmol 2014; 2014: 913047.

15. Kar T, Yildirim Y, Topal T, et al. Efficacy of adjunctive mitomycin $C$ in transcanalicular diode laser dacryocystorhinostomy in different age groups. Eur J Ophthalmol 2016; 26: 1-5.

16. Feijó ED, Caixeta JA, de Souza Nery AC, et al. A comparative study of modified transcanalicular diode laser dacryocystorhinostomy versus conventional transcanalicular diode laser dacryocystorhinostomy. Eur Arch Otorhinolaryngol 2017; 274: 3129-34.

17. Yener HI, Gul A, Caglar C, Ozcimen M. The effectiveness of postoperative early ostium cleaning in transcanalicular diode laser-assisted dacryocystorhinostomy. Ophthal Plast Reconstr Surg 2014; 30: 476-9.

18. Ozsutcu M, Balci O, Tanriverdi C, Demirci G. Efficacy of adjunctive mitomycin $C$ in transcanalicular diode laser dacryocystorhinostomy. Eur Arch Otorhinolaryngol 2017; 274: 873-7.

19. Dogan R, Meric A, Ozsütcü M, Yenigun A. Diode laser-assisted endoscopic dacryocystorhinostomy: a comparison of three different combinations of adjunctive procedures. Eur Arch Otorhinolaryngol 2013; 270: 2255-61.

20. Singh AP, Narula V, Meher R. A new approach to endoscopic DCR. Braz J Otorhinolaryngol 2012; 78: 7-11.

21. Loevschall H, Arenholt-Bindslev D. Effect of low level diode laser irradiation of human oral mucosa fibroblasts in vitro. Laser Surg Med 1994; 14: 347-54.
22. Ben Simon GJ, Brown C, McNab AA. Larger osteotomies result in larger ostia in external dacryocystorhinostomies. Arch Facial Plast Surg 2012; 14: 127-31.

23. Argin A, Görür K, Ozcan C, et al. The role of larger osteotomy in long term success in external dacryocystorhinostomy. J Plast Reconstr Aesthet Surg 2008; 61: 615-9.

24. Pandit VK, Jehan M, Pathak N, et al. To analyse the success rate of external dacryocystorhinostomy related with anatomical osteotomy size made during surgery. Int J Appl Res 2018; 4: 354-8.

Received: 25.06.2018, accepted: 29.08.2018. 